Bull. Chem. Soc. Ethiop. 2021, 35(2), 461-470.

(c) 2021 Chemical Society of Ethiopia and The Authors

ISSN 1011-3924

DOI: https://dx.doi.org/10.4314/bcse.v35i2.18

Printed in Ethiopia

Online ISSN 1726-801X

\title{
SIMULATION STUDIES ON CORROSION OF STONE COATED ROOFING SHEETS
} SOLD IN NIGERIA

\author{
Daniel Omeodisemi Omokpariola ${ }^{1 *}$, Elshalom Chioma Onomeje Omokpariola $^{2}$ \\ and Victor Uchenna Okechukwu ${ }^{1}$ \\ ${ }^{1}$ Environmental Chemistry Unit, Pure and Industrial Chemistry Department, Nnamdi Azikiwe \\ University, Awka, Nigeria \\ ${ }^{2}$ Applied Geophysics Department, Nnamdi Azikiwe University, Awka, Nigeria
}

(Received September 27, 2020; Revised May 4, 2021; Accepted May 7, 2021)

\begin{abstract}
Acid rain condition were simulated on three selected stone-coated roofing sheets sold in Nigeria to assess the rate of metallic dissolution using $(0.25,0.50,0.75$, and $1.00 \mathrm{M})$ concentration of sulfuric acid, simulated acid rain $\left(0.5 \mathrm{M}\right.$ of $\mathrm{HCl}, \mathrm{HNO}_{3}$ and $\left.\mathrm{H}_{2} \mathrm{SO}_{4}\right)$ for 30 days in a controlled environment. Six metals $(\mathrm{Pb}, \mathrm{Fe}$, $\mathrm{Zn}, \mathrm{Al}, \mathrm{Si}$, and $\mathrm{Cd}$ ) concentration were determined using same concentration of sulfuric acid and distilled water for three hours at elevated temperature of $55{ }^{\circ} \mathrm{C}$. The results showed that as concentration increases across the three samples, the corrosion rate of stone-coated roofing sheets increases. The analysis of variance (ANOVA) showed that the weight loss of the samples were significant by all input variables. The fourth order polynomial model conducted for weight loss and corrosion showed best fit with regression $\left(\mathrm{R}^{2}\right)$ which ranged from 0.95 and 0.99 across three samples except for $1.00 \mathrm{M}$ of sulfuric acid at $0.8953,0.8862$, and 0.8933 for Sample 1, 2 and 3, respectively. Metal dissolution conducted for three hours showed that zinc had highest dissolution across different concentration, followed by iron respectively, aluminum dissolved at $0.75 \mathrm{M}$ sulfuric acid; lead dissolved at 0.25 M, $1 \mathrm{M}$ and distilled water while silicon and cadmium had relatively low dissolution accordingly. Acid rain has negative impact on corrosion stone-coated roofing sheets thus influencing its lifespan and durability.
\end{abstract}

KEY WORDS: Simulation, Acid rain, Metal dissolution, Corrosion, Stone-coated roof, Nigeria

\section{INTRODUCTION}

Since the $19^{\text {th }}$ century, roofing materials is constantly been developed and manufactured to protect building from the impact of climatic elements, which are low cost and durable. Different type of roofing sheets such as corrugated iron, galvanized metals, ceramic tiles, polymer roofs, stone-coated roofs etc., have constantly been used in Nigeria to add beauty to buildings. Nevertheless, over time, roofing sheets degrades in quality compared to its original states due to corrosion. Corrosion is the gradual degradation (or denature) by chemical attack on an exposed surface, often a metal, to produces corrosion deposits [1]. Corrosion is an environmental phenomenon, which creates balance, but negatively has economic implication as it costs industries millions of dollars from coating, painting, galvanizing, or anodizing, etc. According to Awajiogak and Emmanuel [2], corrosion reduces the binding energy of metals thus; it is accelerated by acid rain most especially in oil producing environments. This acid rain is due to oxides of sulfur, nitrogen, carbon and phosphorus that are released into the atmosphere, thereafter combines with rain droplets producing acids that initiate corrosion [3, 4]

Industrialization has solved man's problem but create environmental factors from release of anthropogenic gases such as oxides of nitrogen, sulfates, carbon, etc. into the atmosphere which in-turn react with moisture forming reactive ions as wet deposition. Wet deposition of rainwater leads to corrosion of different metals roofing sheets respectively as carrion deposits referred to as rust and leaching [5]. The levels of metals leached by precipitation from roofing strongly depend on the composition of the roof, atmospheric pollution, temperature variation, age of

*Corresponding author. E-mail: omeodisemi@gmail.com

This work is licensed under the Creative Commons Attribution 4.0 International License 
roofing material, residence intensity, and aerial deposition of rainfall [6]. The reaction between roofing sheets and pollutants are very complex and depend on roofing sheet exposure, reactivity and the amount of moisture present. These lead to the deterioration of roofing materials, dissolution and partial oxidation of metals and bioaccumulation of toxic metals in biodiversity $[7,8]$.

Stone-coated roofing material are made from aluminium; zinc coated steel, acrylic resin protective coatings, natural/ceramic stone chips and acrylic over-glaze [9] as shown in Figure 1. Currently, stone-coated roofing material is currently gaining recognition in the building sector in Nigeria. The study aims to evaluate corrosion rate and metal dissolution from acid corrosion of stone-coated roofing sheet in Nigeria.

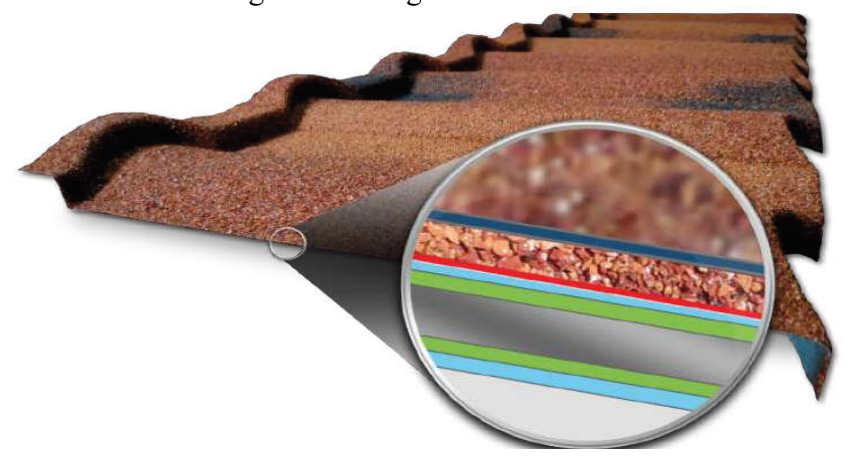

Clear Acrylic Over Glazing Layer aㅐ Volcanic Stones Coating Laye

Adhesive Bonding Layer Acrylic Resin Protective Layer

Aluminium-Zinc Layer

Steel

Aluminium-Zinc Layer

Acrylic Resin Protective Layer

Figure 1. Stone coated sheet [10].

\section{EXPERIMENTAL}

Sample preparation

Three different brands of stone-coated roofing sheets were bought from Korban Technology at Aroma in Akwa South Local Government Area of Anambra State, Nigeria. They were assigned sample identity: Sample 1 (S1), Sample 2 (S2) and Sample 3 (S3). Each samples were cut into small sized sheets per brand having dimension of $4 \mathrm{~cm} \times 4 \mathrm{~cm}$ and a hole of $2 \mathrm{~mm}$ diameter was drilled at the top center of each sheet, cleaned with ethanol to remove dirt, oil and grease and prevent further reaction to sheets.

\section{Reagent preparation}

Concentrated sulfuric acid $\left(\mathrm{H}_{2} \mathrm{SO}_{4}\right)$ was prepared into different concentration of $0.25,0.5,0.75$ and $1.00 \mathrm{M}$, simulated acid rain $\left(0.5 \mathrm{M}\right.$ of $\mathrm{HCl}, \mathrm{HNO}_{3}$ and $\left.\mathrm{H}_{2} \mathrm{SO}_{4}\right)$ and distilled water as reference standard.

\section{Analytical method}

The cut sheets were weighed to obtain initial weight, tied with plastic band, attached to retort stand before immersing into $250 \mathrm{~mL}$ conical flask containing $100 \mathrm{~mL}$ of different concentrations of sulfuric acid and simulated acid rain $\left(0.5 \mathrm{M}\right.$ of $\mathrm{HCl}, \mathrm{HNO}_{3}$ and $\left.\mathrm{H}_{2} \mathrm{SO}_{4}\right)$, respectively, in controlled environment. The weight loss was determined every three (3) days for 30 days.

Same concentration of sulfuric acid and distilled water was heated to $55{ }^{\circ} \mathrm{C}$, using waterbath and sustained for three hours to determine metal deposit concentration. After the boiling 
process, the metal sheets were obtained from the conical flask, washed with running distilled water and bristle brush, air-dried with blow drier and reweighed as final weight. $5 \mathrm{~g}$ of solutions from corrosion process was weighed into a digestion flask and $20 \mathrm{~mL}$ of acetic acid mixture ( $650 \mathrm{~mL}$ concentrated nitric acid; $80 \mathrm{~mL}$ perchloric acid; $20 \mathrm{~mL}$ concentrated sulfuric acid) was added. The flask was heated until a clear digest was obtained. The digest were diluted with distilled water to the $50 \mathrm{~mL}$ beaker and $5 \mathrm{~mL}$ of concentrated nitric acid was added and made up to $100 \mathrm{~mL}$ in volumetric flask before transferring into a pre-treated bottles. Six metals $(\mathrm{Pb}, \mathrm{Fe}$, $\mathrm{Zn}, \mathrm{Al}, \mathrm{Si}$, and $\mathrm{Cd}$ ) were quantified using Agilent atomic absorption spectrophotometer. These were conducted in triplicates for precision measurement.

\section{Statistical method}

Microsoft Excel Package 2019 for Windows was used to execute several statistical analysis using different preinstalled Add-ins XRealStats (Fourth order polynomial regression with oneway ANOVA). Graphical presentations were prepared with cluster column using Excel Charts. ANOVA assess significance of two groups. Polynomial regression utilized for non-linear graph relationship between dependent variable $\mathrm{y}$ and independent variable $\mathrm{x}$ modelled to nth degree. It gives ascertain high degree of accuracy compared to statistical analysis.

Polynomial regression analysis as applied by Oji and Okon [11] were used to model the weight loss and the rates of corrosion of the stone-coated roofing sheets.

Weight loss equation: $\mathrm{y}=\mathrm{at} \mathrm{t}^{4}+\mathrm{bt}^{3}+\mathrm{ct}^{2}+\mathrm{dt}+\mathrm{e}$

where $\mathrm{y}$ is weight loss; $\mathrm{a}, \mathrm{b}, \mathrm{c}, \mathrm{d}$, e are constant and $\mathrm{t}$ is exposure time. The Corrosion rate was determined from equation 1 differentiated to obtain

$R=4 a t^{3}+3 b t^{2}+2 c t+d$

where $\mathrm{R}$ : corrosion rate; $\mathrm{a}, \mathrm{b}, \mathrm{c}, \mathrm{d}$ are constant and $\mathrm{t}$ is exposure time.

\section{RESULTS AND DISCUSSION}

\section{Weight loss from corrosion process}

Figure 2a-e shows a line plot of weight loss ( $g$ ) against time (days) across different concentration of sulfuric acid and simulated acid rain. A survey of each line plot 2a-d showed steady degradation, which is due to the fact that as sulfuric acid $\left(\mathrm{H}_{2} \mathrm{SO}_{4}\right)$ concentration increases, the rate and impact of corrosion. A look at $2 \mathrm{e}$ for simulated acid rain (hydrochloric acid, nitric acid and sulfuric acid) showed that S1 dissolved on the $15^{\text {th }}$ day while S2 and S3 melted on the $18^{\text {th }}$ day. Sulfuric acid, nitric acid and hydrochloric acid is readily soluble in water as it dissociate into respective ions and free hydrogen, which initiate high reactivity rate with metallic compositions. Sulfur oxides $\left(\mathrm{SO}_{\mathrm{x}}\right)$, nitrogen oxides $\left(\mathrm{NO}_{\mathrm{x}}\right)$ and carbon oxides $\left(\mathrm{CO}_{\mathrm{x}}\right)$ are precursor gases, which causes increase corrosion reaction on roofing sheet from anthropogenic releases [12]. Chlorides gets on stone-coated roofs from mining and seawater releases, which combines with dust particles, settle and form corrosive coating on roofing sheet degrading slowly in presence of rainwater [13]. As these combine together in aqueous medium, the $\mathrm{pH}$ decreases leading to creation of active site for hydrogen abstraction by metals ions, which binds readily with dissolved sufate ion or hydroxylion from distilled water used [14]. 

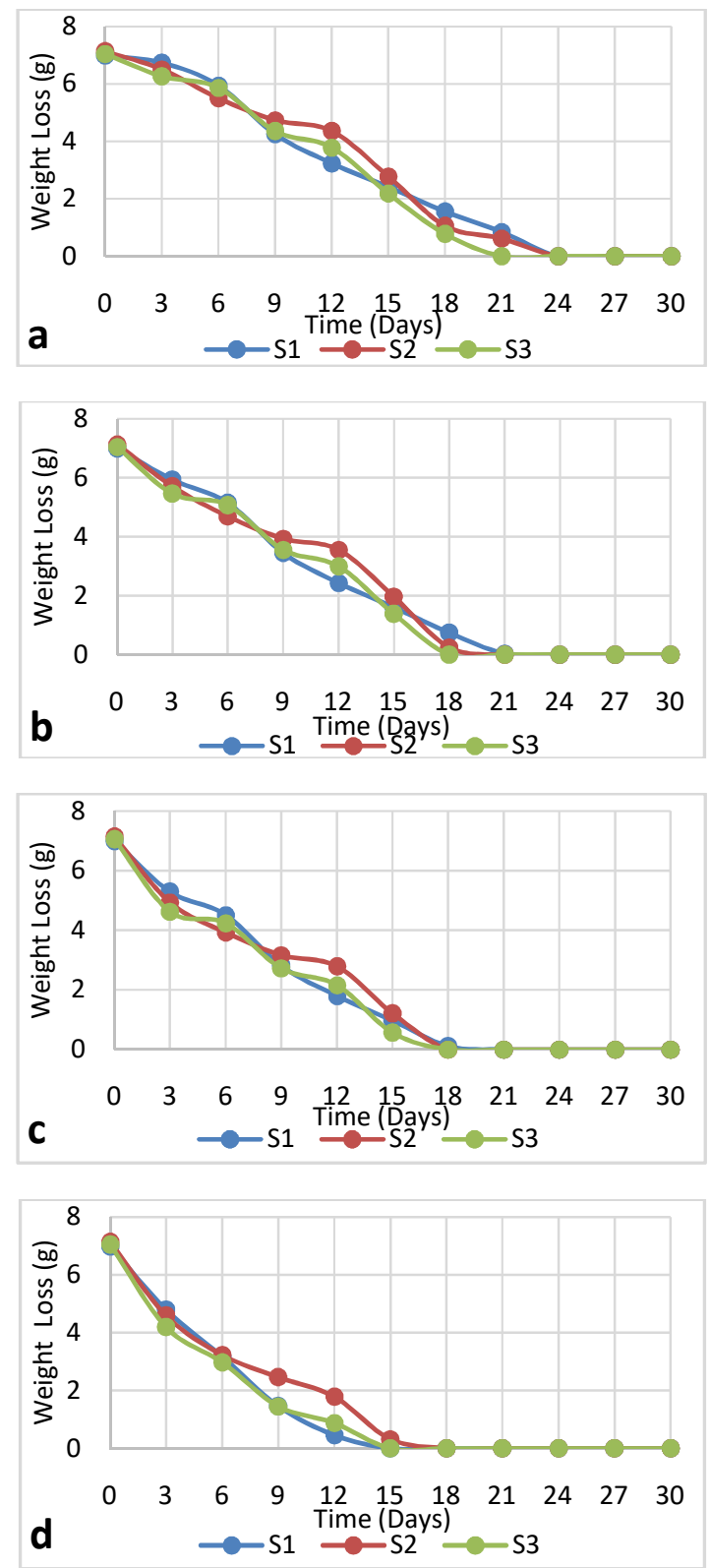

Bull. Chem. Soc. Ethiop. 2021, 35(2) 


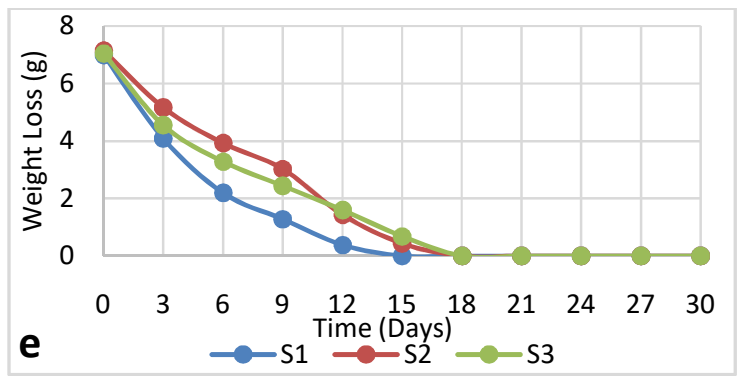

Figure 2. a-e: Line graph for $0.25,0.50,0.75$ and $1.00 \mathrm{M} \mathrm{H}_{2} \mathrm{SO}_{4}$; and simulated acid rain $(0.5 \mathrm{M}$ $\left.\mathrm{HCl}, \mathrm{HNO}_{3}, \mathrm{H}_{2} \mathrm{SO}_{4}\right)$.

\section{ANOVA and polynomial regression}

Table 1 and 2 show ANOVA results and fourth order polynomial model for S1, S2 and S3. ANOVA study showed that various concentration of sulfuric acid and simulated acid rain assessed were significant at $\mathrm{p}<0.05$; regression showed that every concentration of sulfuric acid and simulated acid rain were between 0.95 and 0.99 except for $1 \mathrm{M} \mathrm{H}_{2} \mathrm{SO}_{4}$ were at 0.8953 , 0.8862 , and 0.8933 for S1, S2 and S3, respectively. The results were similar to corrosion studies by Oji and Okon [11], which exhibited increasing metal dissolution from corroding acid medium.

Table 1. Analysis of variance (ANOVA) across different concentration of sulphuric acid and simulated acid rain.

\begin{tabular}{|l|l|l|l|l|l|l|l|}
\hline $0.25 \mathrm{M} \mathrm{H}_{2} \mathrm{SO}_{4}$ & R-square & SE & SS & MS & F-value & $p$-value & Sig. \\
\hline Sample 1 & 0.9956 & 0.2226 & 55.7886 & 13.8852 & 245.9411 & $4.58 \mathrm{E}-06$ & Yes \\
\hline Sample 2 & 0.9945 & 0.2831 & 57.9612 & 11.5281 & 143.8793 & 0.0001 & Yes \\
\hline Sample 3 & 0.9924 & 0.2832 & 58.36645 & 11.6091 & 144.7018 & 0.0001 & Yes \\
\hline $0.50 \mathrm{M} \mathrm{H}_{2} \mathrm{SO}_{4}$ & & & & & & & \\
\hline Sample 1 & 0.9964 & 0.2024 & 45.1422 & 8.9957 & 219.5645 & $5.75 \mathrm{E}-05$ & Yes \\
\hline Sample 2 & 0.9778 & 0.4531 & 46.2771 & 9.1729 & 88.8984 & 0.0003 & Yes \\
\hline Sample 3 & 0.9885 & 0.3208 & 44.9482 & 8.8978 & 77.5024 & 0.0005 & Yes \\
\hline $0.75 \mathrm{M} \mathrm{H}_{2} \mathrm{SO}_{4}$ & & & & & & & \\
\hline Sample 1 & 0.9936 & 0.1614 & 36.4193 & 7.2612 & 256.3827 & $4.22 \mathrm{E}-05$ & Yes \\
\hline Sample 2 & 0.9785 & 0.3794 & 33.4174 & 6.6031 & 65.7180 & 0.0006 & Yes \\
\hline Sample 3 & 0.9899 & 0.2518 & 31.3404 & 6.2054 & 79.2439 & 0.0004 & Yes \\
\hline $1.0 \mathrm{M} \mathrm{H} \mathrm{SO}_{4}$ & & & & & & & \\
\hline Sample 1 & 0.8953 & 0.5515 & 25.6604 & 6.3848 & 1291.293 & $1.68 \mathrm{E}-06$ & Yes \\
\hline Sample 2 & 0.8862 & 0.2656 & 25.58116 & 6.3071 & 67.8523 & 0.0006 & Yes \\
\hline Sample 3 & 0.8933 & 0.4638 & 20.3216 & 5.0468 & 160.9457 & 0.0001 & Yes \\
\hline Simulated acid rain & & & & & & & \\
\hline Sample 1 & 0.9667 & 0.4214 & 26.6482 & 5.2654 & 65.5484 & 0.0006 & Yes \\
\hline Sample 2 & 0.9785 & 0.3026 & 39.7545 & 7.8957 & 114.3797 & 0.0002 & Yes \\
\hline Sample 3 & 0.9886 & 0.3531 & 54.8266 & 10.8732 & 94.3707 & 0.0003 & Yes \\
\hline
\end{tabular}

Where R: regression; SE: standard error; SS: sum of square, MS: mean square; Sig: significance. 
Table 2. Modelling equations for weight loss and corrosion rate across different concentration of sulfuric acid and simulated acid rain.

\begin{tabular}{|c|c|c|}
\hline $0.25 \mathrm{M} \mathrm{H}_{2} \mathrm{SO}_{4}$ & Weight loss equation & Corrosion rate equation \\
\hline Sample 1 & $\begin{array}{l}y=3.81 E-06 x^{4}-0.0003 x^{3}+0.0095 x^{2}- \\
0.1269 x+0.3187\end{array}$ & $\begin{array}{l}\mathrm{y}=2.77 \mathrm{E}-06 \mathrm{t}^{3}+6.04 \mathrm{E}-05 \mathrm{t}^{2}+ \\
0.0004 \mathrm{t}-0.4087\end{array}$ \\
\hline Sample 2 & $\begin{array}{l}y=-9.6 E-06 x^{4}+0.0008 x^{3}-0.0232 x^{2}+ \\
0.2896 x-1.7884\end{array}$ & $\begin{array}{l}\mathrm{y}=-6.1 \mathrm{E}-07 \mathrm{t}^{3}+0.0008 \mathrm{t}^{2}-0.0323 \mathrm{t} \\
+0.0511\end{array}$ \\
\hline Sample 3 & $\begin{array}{l}\mathrm{y}=-5.2 \mathrm{E}-06 \mathrm{x}^{4}+0.0004 \mathrm{x}^{3}-0.0092 \mathrm{x}^{2}+ \\
0.07852 \mathrm{x}-0.4904\end{array}$ & $\begin{array}{l}\mathrm{y}=-4.6 \mathrm{E}-05 \mathrm{t}^{3}+0.00382 \mathrm{t}^{2}-0.0958 \mathrm{t} \\
+0.5059\end{array}$ \\
\hline \multicolumn{3}{|l|}{$0.50 \mathrm{M} \mathrm{H}_{2} \mathrm{SO}_{4}$} \\
\hline Sample 1 & $\begin{array}{l}y=8.55 \mathrm{E}-07 \mathrm{x}^{4}-9.8 \mathrm{E}-05 \mathrm{x}^{3}+0.0041 \mathrm{x}^{2}- \\
0.0676 \mathrm{x}+0.0421\end{array}$ & $\begin{array}{l}\mathrm{y}=2.75 \mathrm{E}-05 \mathrm{t}^{3}+0.002 \mathrm{t}^{2}-0.0391 \mathrm{t}- \\
0.1211\end{array}$ \\
\hline Sample 2 & $\begin{array}{l}\mathrm{y}=-1.2 \mathrm{E}-06 \mathrm{x}^{4}+0.0009 \mathrm{x}^{3}-0.0261 \mathrm{x}^{2}+ \\
0.3171 \mathrm{x}-1.89601\end{array}$ & $\begin{array}{l}\mathrm{y}=-3.0 \mathrm{E}-05 \mathrm{t}^{3}+0.0027 \mathrm{t}^{2}-0.0686 \mathrm{t} \\
+0.3082\end{array}$ \\
\hline Sample 3 & $\begin{array}{l}y=-3.5 E-06 x^{4}+0.0002 x^{3}-0.0034 x^{2}- \\
0.00437 x-0.01143\end{array}$ & $\begin{array}{l}\mathrm{y}=-7.2 \mathrm{E}-05 \mathrm{t}^{3}+0.0053 \mathrm{t}^{2}-0.1202 \mathrm{t} \\
+0.6504\end{array}$ \\
\hline \multicolumn{3}{|l|}{$0.75 \mathrm{M} \mathrm{H}_{2} \mathrm{SO}_{4}$} \\
\hline Sample 1 & $\begin{array}{l}\mathrm{y}=1.92 \mathrm{E}-06 \mathrm{x}^{4}-0.0002 \mathrm{x}^{3}+0.008 \mathrm{x}^{2}- \\
0.1242 \mathrm{x}+0.3748\end{array}$ & $\begin{array}{l}\mathrm{y}=-4.8 \mathrm{E}-05 \mathrm{t}^{3}+0.0324 \mathrm{t}^{2}-0.0602 \mathrm{t} \\
+0.0091\end{array}$ \\
\hline Sample 2 & $\begin{array}{l}y=-8.3 \mathrm{E}-06 \mathrm{x}^{4}+0.0006 \mathrm{x}^{3}-0.0177 \mathrm{x}^{2}+ \\
0.2097 \mathrm{x}-1.3279\end{array}$ & $\begin{array}{l}\mathrm{y}=-3.8 \mathrm{E}-05 \mathrm{t}^{3}+0.0029 \mathrm{t}^{3}-0.0678 \mathrm{t} \\
+0.2578\end{array}$ \\
\hline Sample 3 & $\begin{array}{l}y=9.13 E-07 x^{4}-0.0002 x^{3}+0.0072 x^{2}- \\
0.1359 x+0.6621\end{array}$ & $\begin{array}{l}y=-7.2 \mathrm{E}-05 \mathrm{t}^{3}+0.005 \mathrm{t}^{3}-0.1054 \mathrm{t}+ \\
0.4879\end{array}$ \\
\hline \multicolumn{3}{|l|}{$1.00 \mathrm{M} \mathrm{H}_{2} \mathrm{SO}_{4}$} \\
\hline Sample 1 & $\begin{array}{l}y=4.77 \mathrm{E}-06 \mathrm{x}^{4}-0.0004 \mathrm{x}^{3}+0.01206 \mathrm{x}^{2}- \\
0.1315 \mathrm{x}+0.0111\end{array}$ & $\begin{array}{l}\mathrm{y}=-1.3 \mathrm{E}-05 \mathrm{t}^{3}+0.0002 \mathrm{t}^{2}+0.0281 \mathrm{t} \\
-0.9006\end{array}$ \\
\hline Sample 2 & $\begin{array}{l}y=-3.4 E-06 x^{4}+0.0003 x^{3}-0.0063 x^{2}+ \\
0.0768 x-0.774\end{array}$ & $\begin{array}{l}\mathrm{y}=-3.4 \mathrm{E}-05 \mathrm{t}^{3}+0.0022 \mathrm{t}^{2}-0.0381 \mathrm{t} \\
-0.1172\end{array}$ \\
\hline Sample 3 & $\begin{array}{l}y=2.7 \mathrm{E}-06 x^{4}-0.0002 x^{3}+0.0077 x^{2}- \\
0.0901 x-0.0194\end{array}$ & $\begin{array}{l}\mathrm{y}=-2.1 \mathrm{E}-05 \mathrm{t}^{3}+0.001 \mathrm{t}^{2}+0.0004 \mathrm{t}- \\
0.5362\end{array}$ \\
\hline \multicolumn{3}{|c|}{ Simulated acid rain } \\
\hline Sample 1 & $\begin{array}{l}\mathrm{y}=1.11 \mathrm{E}-05 \mathrm{x}^{4}-0.001 \mathrm{x}^{3}+0.031 \mathrm{x}^{2}-0.42 \mathrm{x} \\
+1.9076\end{array}$ & $\begin{array}{l}\mathrm{y}=-5.9 \mathrm{E}-05 \mathrm{t}^{3}+0.0035 \mathrm{t}^{2}-0.0495 \mathrm{t} \\
-0.2099\end{array}$ \\
\hline Sample 2 & $\begin{array}{l}y=6.28 E-06 x^{4}-0.0006 x^{3}+0.0223 x^{2}- \\
0.3437 x+1.7733\end{array}$ & $\begin{array}{l}\mathrm{y}=-1.0 \mathrm{E}-04 \mathrm{t}^{3}+0.0066 \mathrm{t}^{2}-0.1337 \mathrm{t} \\
+0.5735\end{array}$ \\
\hline Sample 3 & $\begin{array}{l}y=-5.9 E-06 x^{4}+0.0004 x^{3}-0.01 x^{2}+0.09 x \\
-0.611\end{array}$ & $\begin{array}{l}\mathrm{y}=-6.3 \mathrm{E}-05 \mathrm{t}^{3}+0.0047 \mathrm{t}^{2}-0.1088 \mathrm{t} \\
+0.5233\end{array}$ \\
\hline
\end{tabular}

\section{Metal dissolution}

Figure 3 shows the bar chart from metallic dissolution of stone-coated roofing sheets at different sulfuric acid concentration with distilled water as control at elevated temperature for 3 hours. Aluminum had slight increase at $0.75 \mathrm{M} \mathrm{H}_{2} \mathrm{SO}_{4}$ concentration for $\mathrm{S} 1$ and $\mathrm{S} 2$ with low dissolution potentials for S3. Cadmium had low dissolution at $\mathrm{S} 1$ and high dissolution for S2 and $\mathrm{S} 3$ at $0.25 \mathrm{M} \mathrm{H}_{2} \mathrm{SO}_{4}$. Iron had highly soluble in across different $\mathrm{H}_{2} \mathrm{SO}_{4}$ concentration respectively. Lead showed increased dissolution in $0.25 \mathrm{M} \mathrm{H}_{2} \mathrm{SO}_{4}$ for $\mathrm{S} 1$ only with sharp decrease and slight increase as concentration progresses across all samples. Silicon dissolved at a low rate indicating less reactivity across the different concentration for S1; S2 and S3 had high reactivity and dissolution across different concentration. Zinc dissolved highest across different $\mathrm{H}_{2} \mathrm{SO}_{4}$ concentration for $\mathrm{S} 1$ to $\mathrm{S} 3$.In aqueous medium of sulfate ion, the influence of hydrogen ion $(\mathrm{pH})$, electron potential (Eh), and ionic strength affects the combining prospects for metallic ion at different concentration that may be either at equilibrium or subject to redox chemical transformation, respectively [15]. Metals can react with sulfates ion to form aqueous complexes, 
which may be precipitated out or undergo further complexing reactions at different oxidation states for the case of aluminum, cadmium, lead, iron, zinc, and silicon ions, respectively [1618]. Looking at the metal dissolution value of distilled water all analyzed metals have potential to form hydroxyl ion at elevated temperature that indicate that these metals can undergo redoxdriven cycles across aqueous medium by adsorption under oxidizing conditions with moderate reduction to oxy-hydroxides respectively [19].

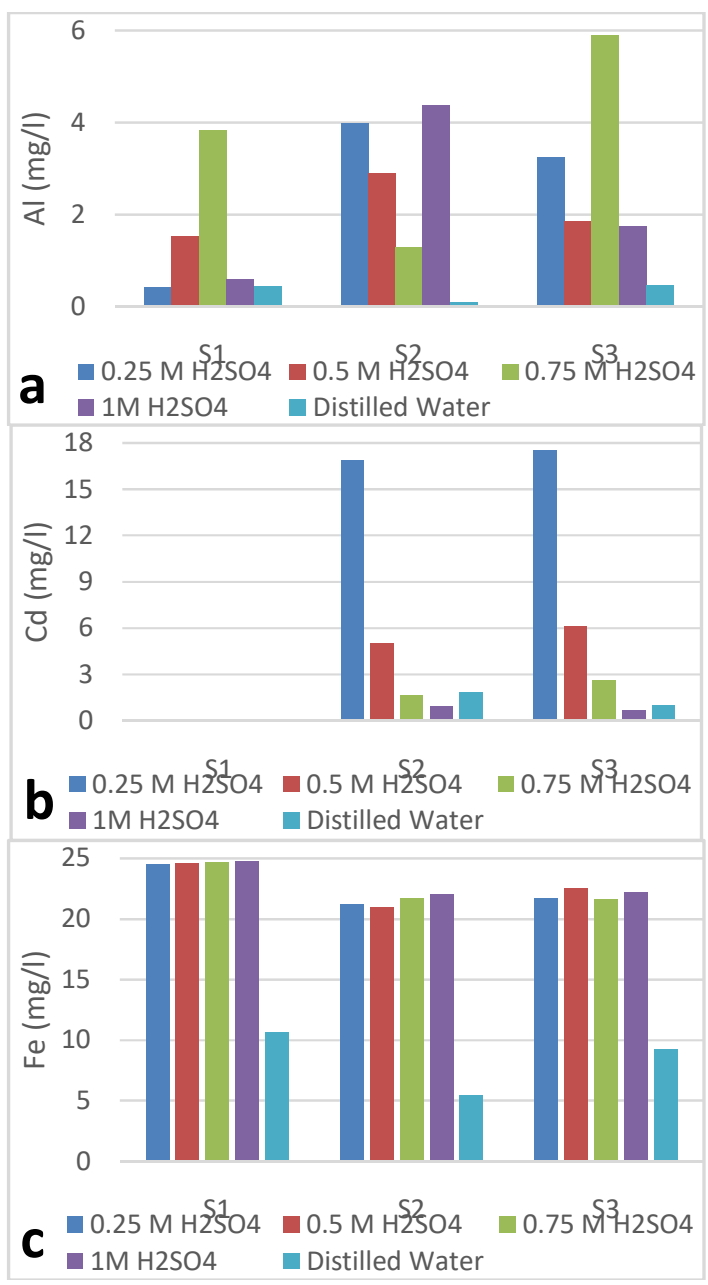




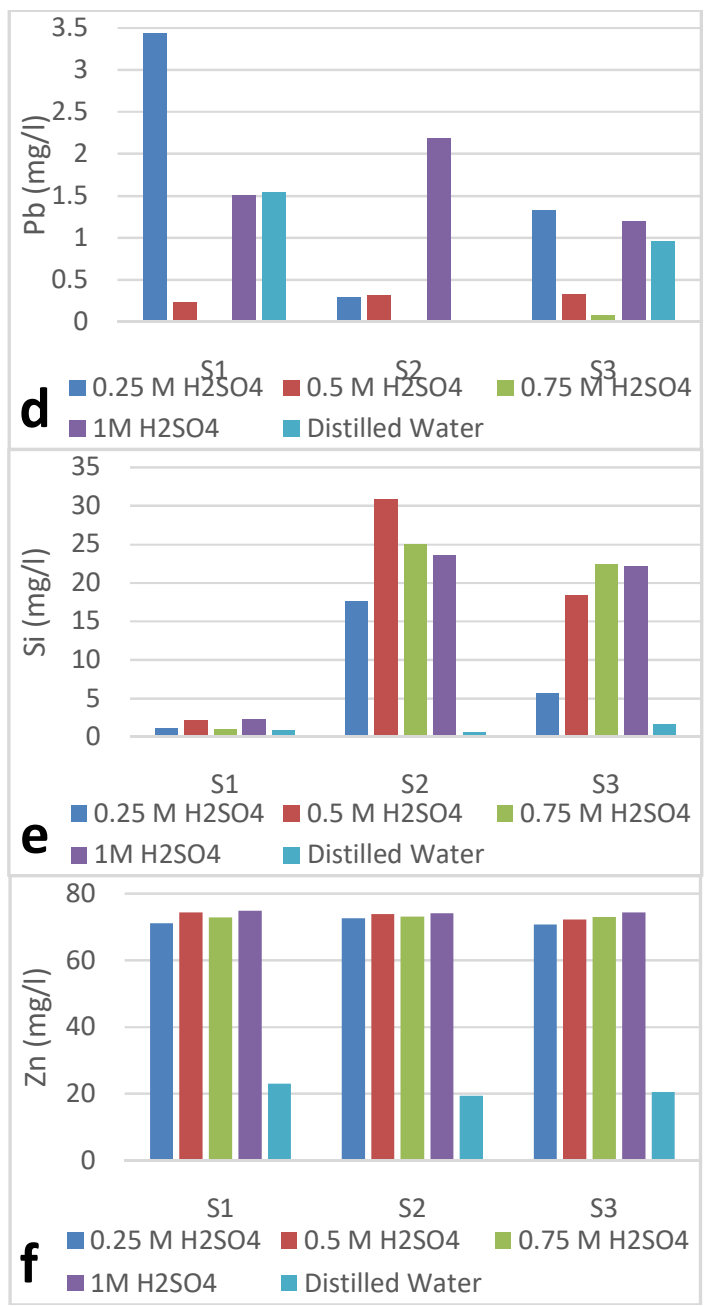

Figure 3. a-f: Bar chart indicating different metal dissolution.

\section{CONCLUSION}

From the simulation study, we assessed the impact of acid corrosion on three sampled stonecoated roofing sheets sold in Nigeria and discovered that the stone-coated roofing sheets had increased deposit with grey and brown coloration after several days as ANOVA showed $\mathrm{p}<$ 0.05 were significant. The extents of attack of the roofing sheet depended majorly on the concentration level of the pollutant. Fourth order polynomial regression conducted on weight loss and corrosion rate ranged from 0.8622 and 0.9956 across various concentration of sulfuric acid and simulated acid rain for a period of 30 days. Metal dissolution of stone-coated samples heated in aqueous medium of sulphuric acid and distilled water showed that elevated temperature impacts on corrosion potential from redox reaction on roofing sheet durability. 
Therefore, manufacturing companies' needs to improve on the bonding processes to aid durability of stone-coated roofing sheet as Nigeria atmospheric condition is not favourable for the stone-coated roof material over long period leading to chemical leaching.

\section{ACKNOWLEDGEMENTS}

The authors wish to acknowledge laboratory technicians and students of Pure and Industrial Chemistry, Nnamdi Azikiwe University, Awka, Nigeria for their assistance during the research work.

\section{REFERENCES}

1. Corrosion. Encyclopædia Britannica Ultimate Reference Suite. Encyclopædia Britannica, Chicago, 2014.

2. Awajiogak, A.U.; Emmanuel, O.E. Establishing kinetic processes of corrosion on zinc/iron roofing sheet in coastal/ industrial environment. Int. J. Appl. Eng. Technol. 2013, 3, 9-17.

3. Omokpariola, D.O. Summary of National and Global Environmental Issues. Research Gate 2019, 1-12. http://dx.doi.org/10.13140/RG.2.2.35672.21767.

4. Omokpariola, D.O.; Nduka, J.K.; Omokpariola, P.L.; Omokpariola, E.C.O. Ionic composition of rainwater from different sampling surfaces across selected locations in Rivers, Nigeria. World Scientific News 2020, 150, 132-147.

5. Obia, A.E.; Obot, I.D. Atmospheric corrosion of metallic roofing sheet in building construction in the Niger Delta region of Nigeria. J. Environ. Issues Agric. Develop. Countries 2010, 2, 2-3.

6. Mendez, C.B.; Klenzendorf, J.B.; Afshar, B.R.; Simmons, M.T.; Barrett, M.E.; Kinney, K.A.; Kirisits, M.J. The effect of roofing material on the quality of harvested rainwater. Water Res. 2011, 45, 2049-2059.

7. Abdulkarim, B.I.; Abdullahi, Y.A.; Salam, K.A. Corrosion Resistance of commercial roofing sheets to acid rain water in Eleme, Rivers, Nigeria. Int. J. Chem. Technol. Res. 2009, 1, 802-806.

8. US-EPA. Health assessment document for diesel engine exhaust. Prepared by the National Center for Environmental Assessment, Washington, DC, for the Office of Transportation and Air Quality; EPA/600/8-90/057F. National Technical Information Service, Springfield, VA; PB2002-107661, 2002. Available at: http://www.epa.gov/ncea.

9. Dofasco. Steel material safety data sheets (MSDS). 2007. Available at: http://wcm.pavliks.com/WCMAdmin/Images/wwwbmpgroupcom/CustomerServiceImages/ MSDSsheets.pdf.

10. DECRA. Volcanic stone coated metal roof, 2016. Available at: www.decra.com/PDF/DECRA_LEED-Homes.pdf.

11. Oji, A.; Okon, A.I. Evaluation and modelling of corrosion rate of selected roofing sheets using tetraoxosulfate(VI) acid and trioxonitrate(V) acid as simulated acid rain. Chem. Sci. Int. J. 2020, 28, 1-9.

12. Nduka, J.K.C.; Orisakwe, O.E.; Ezenweke, L.O.; Ezenwa, T.E.; Chendo, M.N.; Ezeabasili, N.G. Acid rain phenomenon in Niger Delta Region of Nigeria: Economic, biodiversity and public health concern. The Scientific World J. 2008, 8, 811-818.

13. Igbinosa, I.H.; Aighewi, I.T. Assessment of the physicochemical and heavy metal qualities of rooftop harvested rainwater in a rural community. Global Challenges 2017, 1-7.

14. Ovri, J.E.O. Corrosion of roofing sheets in a simulated environment. Int. J. Min. Sci. 2017, $3,1-8$. 
15. Geochemical Facies. Encyclopædia Britannica Ultimate Reference Suite. Encyclopædia Britannica, Chicago, 2014.

16. Seigneur, C.; Constantinou, E. Chemical kinetic mechanism for atmospheric chromium. Environ. Sci. Technol. 1995, 29, 222-231.

17. Ubuoh, E.A.; Nwakanma, C.; Ogbuji, S. Atmospheric corrosion of corrugated iron roofing sheet in oil producing locations in Southeastern Nigeria. J. Environ. Anal. Toxicol. 2017, 7, 2161-2167.

18. Ujam, A.J.; Egbuma, S.O.; Idogulu, S. Performance characteristics of various corrugated roofing sheets in Nigeria. Int. J. Computat. Eng. Res. 2014, 4, 2250-3005.

19. US-EPA. Framework for Metals Risk Assessment EPA 120/R-07/001. U.S. Environmental Protection Agency Washington, DC 20460, 2007. Available at: www.epa.gov/osa. 